\title{
Association of Genetic Polymorphisms of Vascular Endothelial Growth Factor and Risk for Proliferative Retinopathy of Prematurity
}

\author{
ÁDÁM VANNAY, GYÖRGY DUNAI, ILONA BÁNYÁSZ, MIKLÓS SZABÓ, RITA VÁMOS, \\ ANDRÁS TRESZL, JÚLIA HAJDÚ, TIVADAR TULASSAY, AND BARNA VÁSÁRHELYI \\ Research Group for Paediatrics and Nephrology [A.V., T.T., B.V.], Hungarian Academy of Sciences, \\ Budapest, Hungary; First Department of Paediatrics [G.D., I.B., M.S., A.T., T.T.], Semmelweis University, \\ Budapest, Hungary; and Second Department of Ophthalmology [R.V., J.H.], Semmelweis University, \\ Budapest, Hungary
}

\begin{abstract}
The intention of our retrospective study was to determine whether vascular endothelial growth factor (VEGF) genetic polymorphisms are associated with risk for proliferative retinopathy of prematurity (ROP), a condition that is characterized by abnormal retinal neovascularization and can lead to retinal detachment and result in blindness. We enrolled 86 very low birth weight infants (birth weight $\leq 1500 \mathrm{~g}$ ) who had been treated with cryo/laser therapy because of the risk for proliferative ROP (treated group). Their VEGF $\mathrm{T}^{-460} \mathrm{C}$ and $\mathrm{G}^{+405} \mathrm{C}$ genotypes were determined from dried blood samples and were compared with VEGF genotypes of 115 VLBW infants who were not treated with cryo/laser therapy (untreated group). We found that the allele frequency of $\mathrm{VEGF}{ }^{+405} \mathrm{C}$ was higher in the treated group than in the untreated group (0.30 versus $0.41 ; p<0.05)$. The likelihood of being treated for ROP was higher in heterozygous and homozygous carriers of VEGF ${ }^{+405} \mathrm{C}$ alleles [odds
\end{abstract}

\section{ABSTRACT}

ratios adjusted for risk factors of ROP (95\% CI): 2.00 (1.02$3.92 ; p=0.04)$ and $3.37(1.17-9.65 ; p=0.007)$, respectively]. VEGF ${ }^{-460} \mathrm{TT} /{ }^{+405} \mathrm{CC}$ haplotype was more prevalent in the treated patients than in the untreated patients (13 of 86 versus 1 of 115; $p<0.001$ ), and the association remained significant ( $p<$ $0.01)$ even after the adjustment for risk factors of ROP (gestational age, supplemental oxygen therapy, and gender). These findings suggest that the VEGF genotype may be associated with risk for proliferative ROP in VLBW infants. (Pediatr Res 57: 396-398, 2005)
ROP, retinopathy of prematurity
SNP, single-nucleotide polymorphism
VEGF, vascular endothelial growth factor
VLBW, very low birth weight

Retinopathy of prematurity (ROP) is a retinal vascular disease of neonates who are born prematurely. Whereas milder forms of ROP evolve in the majority of extremely preterm neonates $(>90 \%)$, the more severe (i.e. proliferative) form of ROP affects $5 \%$ of infants (1). ROP is characterized by the abnormal development of the vessels in the back of the eye and can cause retinal detachment and result in permanent blindness.

The first phase of ROP is due to the sudden postnatal increase of tissue oxygen tension. As a result, the normal in utero development of retinal vasculature ceases, even with some loss of the developed vessels. The second phase develops at approximately

Received January 12, 2004; accepted August 12, 2004.

Correspondence: Ádám Vannay, M.D., 1st Department of Paediatrics Semmelweis University 1083 Budapest, Bókay J. u. 53-54, Hungary; e-mail: vannay@gyer1.sote.hu.

This study was supported with funds from OTKA Grant T046086, ETT 16/2000, and $\mathrm{K}+\mathrm{F}$ 0134/2001.

DOI: 10.1203/01.PDR.0000153867.80238.E0 the 34th postconceptional week. It is hypoxia driven and characterized by retinal neovascularization (2).

The presence of vascular endothelial growth factor (VEGF) is necessary for normal in utero retinal angiogenesis. During the first phase of ROP, the retinal synthesis of VEGF decreases; during the second phase, the inadequate retinal oxygenation triggers abnormal angiogenesis and acts as a survival factor for newly formed abnormal retinal vessels $(3,4)$. The importance of VEGF in the development of ROP is supported by a number of experimental and clinical data. Increased VEGF synthesis and high levels were observed in hypoxic retina $(5,6)$, whereas in other experiments, the inhibition of VEGF prevented retinal ischemia-associated neovascularization $(7,8)$.

The VEGF gene is highly polymorphic, with registered polymorphic loci numbering $>70$ (NCBI, gene accession nos. AF095785 and AF437895). Of those, the significance of several polymorphisms has been suggested in different disorders. Recent studies revealed that haplotypes of single-nucleotide polymor- 
phisms (SNPs) at site $-460\left(\mathrm{~T}^{-460} \mathrm{C}\right)$ and $+405\left(\mathrm{G}^{+405} \mathrm{C}\right)$ are associated with diabetic retinopathy $(9,10)$, possibly through their effect on the inducibility of VEGF synthesis $(11,12)$. Assuming that VEGF plays a central role in abnormal retinal angiogenesis both in diabetic retinopathy and in ROP, we tested whether these VEGF SNPs are associated with the risk for proliferative ROP of very low birth weight (VLBW) infants.

\section{METHODS}

Patients. Each patient had been born with VLBW (birth weight $\leq 1500 \mathrm{~g}$ ) between 2000 and 2003. They were treated at the participating neonatal intensive care unit centers: the Ágost Schöpf-Mérei Institute of Obstetrics, the 1st Department of Gynecology and Obstetrics, and the 2nd Department of Gynecology and Obstetrics, Semmelweis University, Budapest. At the beginning of therapy at the neonatal intensive care unit, informed consent of the parents was obtained to collect dried blood samples from their infants for diagnostic and scientific purposes. An Independent University Ethical Committee approved our retrospective study (license no. 13/2003).

The treated group consisted of infants $(n=128)$ who underwent cryotherapy/photocoagulation because of the high risk for proliferative ROP (Table 1) The risk for proliferative ROP was assessed, and therapy was based on the recommendations of two of three consulting neonatal ophthalmologists, in line with the guidelines of the 2nd Department of Ophthalmology, Semmelweis University. The maximal stage of ROP was based on an international classification system (13). Dried blood samples were available for 92 infants, including 80 single infants and 6 pairs of twins. Of the twins, only one sibling with the more severe maximal stage of ROP was enrolled, bringing the number of treated patients in the study to 86 . The stage of ROP in this group was 2 with plus symptoms (2-plus) in 19 of the infants, 3 in 52 of the infants, 4 in 6 of the infants, and 5 in 9 of the infants.

For the control (untreated) group, we enrolled 145 VLBW single infants who had not undergone cryotherapy/photocoagulation (Table 1). These infants were randomly selected from institutional registries. Dried blood samples were available for 75 infants with ROP stages $0-1$ and 40 infants with maximal ROP stage 2.

Gestational age and birth weight were the same for treated and untreated infants; however, the boy:girl ratio tended to be higher in the treated group than in the untreated group $(p=0.12$; Table 1$)$.
Genotyping. DNA was extracted from filter papers with an extracting agent (Chelex; BioRad, Germany) according to the manufacturers' instructions. VEGF $T^{-460} \mathrm{C}$ SNP was determined by real-time PCR quantification using fluorescence resonance energy transfer hybridization probes on a Light Cycler system (Roche Diagnostics, Mannheim, Germany). Primers and probes were as follows: forward primer 5'-AGACGGCAGTCACTAG-3', and reverse primer 5'-AATATTGAAGGGGGCAG-3'; one probe (5'-AGCGGGGAGAAGGCCAGGG-3') was labeled at the 5' end with the Light Cycler Red 640 fluorophore, and the other one (5'-TGTGGGGTTGAGGGCGTT-3') was labeled at the 3 ' end with fluorescein (Tibmolbiol, Berlin, Germany).

VEGF gene $\mathrm{G}^{+405} \mathrm{C}$ SNP was detected with a restriction fragment length polymorphism method by BsmF I digestion (New England Biolabs, Beverley, MA) of the 197-bp length PCR product, amplified by the following primers: forward 5'-CCGACGGCTTGGGGAGATTG-3' and reverse 5'-CGGCGGTCACCCCCAAAAG-3'. The condition of PCRs was as follows: $30 \mathrm{~s}$ at $94^{\circ} \mathrm{C}$ (denaturing), $60 \mathrm{~s}$ at $60^{\circ} \mathrm{C}$ (annealing), and $30 \mathrm{~s}$ at $72^{\circ} \mathrm{C}$ (extension) for 40 cycles. PCR products were separated on $3 \%$ agarose gels and visualized under UV illumination.

Data analysis. Hardy-Weinberg equilibrium of VEGF -406 and +405 SNPs was calculated using Harlequin-software (http://anthropologie.unige.ch/ arlequin/). For statistical analysis, $\chi^{2}$ test was used to compare allelic and genotype frequencies in infants with treated and with nontreated ROP. Logistic regression analysis was used for the analysis of the association between VEGF genotype and haplotype and need for cryotherapy/photocoagulation. The association was adjusted for gender, length of supplemental oxygen therapy, and gestational age, all proven risk factors of ROP (1).

\section{RESULTS}

The prevalence of VEGF ${ }^{-460} \mathrm{C}$ and ${ }^{+405} \mathrm{C}$ alleles in untreated infants was similar to healthy reference values in adults, according to other publications $(11,12)$. Both genotypes were in HardyWeinberg equilibrium, irrespectively of ROP treatment.

The prevalence of VEGF ${ }^{-460} \mathrm{C}$ allele did not differ in infants with treated and in those with nontreated ROP (Table 1). The prevalence of VEGF ${ }^{+405} \mathrm{C}$ allele was higher in treated than in untreated infants $(p<0.05)$. The heterozygous and homozygous carrier state of VEGF ${ }^{+405} \mathrm{C}$ alleles presented an independent risk

Table 1. VEGF genetic polymorphisms in preterm infants who were treated with cryotherapy/photocoagulation because of risk for severe $R O P$

\begin{tabular}{|c|c|c|}
\hline & $\begin{array}{l}\text { Infants who were not treated with } \\
\text { cryotherapy/photocoagulation }\end{array}$ & $\begin{array}{l}\text { Infants who were treated with } \\
\text { cryotherapy/photocoagulation }\end{array}$ \\
\hline Patients [n (boys/girls)] & $115(60 / 55)$ & $86(55 / 31)$ \\
\hline \multicolumn{3}{|l|}{ ROP stage (no. of patients) } \\
\hline 2 & 40 & \\
\hline $2+$ & & 19 \\
\hline 3 & & 52 \\
\hline Gestational age at birth (wk) & $29.2 \pm 2.9$ & $28.5 \pm 2.0$ \\
\hline Birth weight $(\mathrm{g})$ & $1200 \pm 270$ & $1160 \pm 300$ \\
\hline Days on supplemental oxygen therapy & $7(0-47)$ & $15(0-92)$ \\
\hline \multicolumn{3}{|l|}{ VEGF $\mathrm{T}^{460} \mathrm{C}$ genotype } \\
\hline Prevalence of ${ }^{-460} \mathrm{C}$ allele & 0.47 & 0.41 \\
\hline \multicolumn{3}{|c|}{ Prevalence of VEGF $\mathrm{T}^{-460} \mathrm{C}$ genotype (\%) } \\
\hline Prevalence of ${ }^{+405} \mathrm{C}$ allele & 0.30 & $0.41 *$ \\
\hline \multicolumn{3}{|c|}{ Prevalence of VEGF $\mathrm{G}^{+405} \mathrm{C}$ genotype (\%) } \\
\hline GG & 48 & 35 \\
\hline GC & 46 & 48 \\
\hline $\mathrm{CC}$ & 6 & $17 \dagger$ \\
\hline
\end{tabular}

Birth weight and gestational age are presented as mean $\pm \mathrm{SD}$; length of supplemental oxygen therapy is indicated as median (range).

* OR, Adjusted for gender, length of oxygen supplementation, and gestational age (95\% CI) for VEGF ${ }^{+405} \mathrm{C}$ carriers: $2.00(1.02-3.92) ; p=0.045$.

$\dagger$ Adjusted OR (95\% CI): 3.37 (1.17-9.65); $p=0.011$. 
factor [adjusted odds ratios (OR) (95\% CI): 2.00 (1.02-3.92; $p=$ $0.045)$ and 3.37 (1.17 -9.65; $p=0.011)$, respectively; Table 1].

The results of haplotype analysis are summarized in Table 2. VEGF ${ }^{-460} \mathrm{TT} /{ }^{+405} \mathrm{CC}$ haplotype was associated with increased likelihood of treatment against proliferative ROP even after the adjustment of the association on gestational age, supplemental oxygen therapy, and gender [OR (95\% CI): 16.2 $(1.96-134) ; p=0.01]$. To the contrary, VEGF ${ }^{-460} \mathrm{TT} /$ ${ }^{+405} \mathrm{GG}$ decreased the likelihood, although the strength of association just met the level of significance [adjusted OR (95\% CI): 0.25 (0.06-1.10); $p=0.067$; Table 2].

\section{DISCUSSION}

Our results suggest that the VEGF $\mathrm{G}^{+405} \mathrm{C}$ genotype of VLBW infants is associated with the risk for ROP requiring cryotherapy/photocoagulation. Whereas carriers of ${ }^{-460} \mathrm{TT} /$ ${ }^{+405} \mathrm{CC}$ haplotype may be at increased risk for proliferating ROP, ${ }^{-460} \mathrm{TT} /{ }^{+405} \mathrm{GG}$ haplotype seems to be preventive against the disease. The association between VEGF haplotype and ROP is probably independent of gender, supplemental oxygen therapy, and gestational age, which are verified risk factors for the disease (2). At the evaluation of these findings, however, one should take into account the relatively small size of the enrolled populations, which limits the conclusions that can be drawn from the results of our study.

Similar to our findings, Awata et al. (9) and Stevens et al. (12) also found that the risk for diabetic retinopathy is associated with some haplotypes of VEGF $\mathrm{T}^{-460} \mathrm{C}$ and VEGF $\mathrm{G}^{+405} \mathrm{C}$ SNPs. Our results confirm the association of VEGF genotypes in VLBW infants with risk for ROP requiring cryotherapy/photocoagulation.

It is tempting to speculate that the association between VEGF genotype and ROP risk is the result of increased VEGF production. Awata et al. (9) measured the highest VEGF serum levels in patients who are homozygous for VEGF ${ }^{+405} \mathrm{C}$ alleles. Watson et al. (11), however, saw the opposite results while investigating lipopolysaccharide-induced leukocytes, demonstrating the highest VEGF levels in individuals with ${ }^{+405}$ GG genotype. This apparent inconsistency between studies may be caused in part by different methods and experimental models.

Table 2. Most prevalent haplotypes of VEGF $T^{-460} C$ and $G^{+405} C$ polymorphisms in infants with and without proliferative retinopathy (ROP and control group, respectively)

\begin{tabular}{lcc}
\hline & $\begin{array}{c}\text { Infants who } \\
\text { were not treated } \\
\text { with } \\
\text { cryotherapy/ } \\
\text { photocoagulation } \\
(\% ; n=115)\end{array}$ & $\begin{array}{c}\text { Infants who } \\
\text { were treated } \\
\text { with } \\
\text { cryotherapy/ } \\
\text { photocoagulation } \\
(\% ; n=86)\end{array}$ \\
\hline${ }^{-46 G F ~} T^{-460} \mathrm{C} / \mathrm{G}^{+405} \mathrm{C}$ haplotype & 12 & 13 \\
${ }^{-460} \mathrm{CC} /{ }^{+405} \mathrm{GG}$ & 8 & 1 \\
${ }^{-460} \mathrm{CC} /{ }^{+405} \mathrm{GC}$ & 3 & 0 \\
${ }^{-460} \mathrm{CC} /{ }^{+405} \mathrm{CC}$ & 24 & 17 \\
${ }^{-460} \mathrm{TC} /{ }^{+405} \mathrm{GG}$ & 26 & 35 \\
${ }^{-460} \mathrm{TC} /{ }^{+405} \mathrm{GC}$ & 3 & 2 \\
${ }^{-460} \mathrm{TC} /{ }^{+405} \mathrm{CC}$ & $11 *$ & 5 \\
${ }^{-460} \mathrm{TT} /{ }^{+405} \mathrm{GG}$ & 12 & 12 \\
${ }^{-460} \mathrm{TT} /{ }^{+405} \mathrm{GC}$ & 1 & $15 \dagger$ \\
${ }^{-460} \mathrm{TT} /{ }^{+405} \mathrm{CC}$ & & \\
\hline
\end{tabular}

\footnotetext{
* Adjusted OR (95\% CI): $0.25(0.06-1.10) ; p=0.067$.

$\dagger$ Adjusted OR (95\% CI): $16.2(1.96-134) ; p=0.01$.
}

It is also conceivable that the observed association is not directly related to VEGF production capacity. The VEGF gene is located near the $\mathrm{MHC}$ region on chromosome 6 . The genes of several proteins that are possibly implicated in retinopathy [e.g. heat shock protein 70 (14), tumor necrosis factor- $\alpha$ (15)] are also located here. Therefore, it is possible that the observed association between treated ROP and VEGF gene genotype is the result of linkage disequilibrium with other neighboring, still undefined gene mutations.

In conclusion, we observed a high prevalence of VEGF ${ }^{+405} \mathrm{C}$ allele and VEGF ${ }^{-460} \mathrm{TT} /{ }^{+405} \mathrm{CC}$ haplotype in VLBW infants who were treated with cryotherapy/photocoagulation because of risk for proliferative ROP. These findings suggest that testing of these VEGF SNPs would provide valuable information for the risk assessment of ROP.

Acknowledgments. A.V. and B.V. had primary responsibility for protocol development, patient screening, enrollment, preliminary data analysis, and writing of the manuscript. R.V. and J.H. screened and enrolled patients and participated in the clinical interpretation of the results. G.D. and I.B. participated in the development of the protocol and analytic framework for the study and contributed to the writing of the manuscript. A.T. and M.S. were responsible for the analytical data and for analysis and interpretation. T.T. supervised the design and execution of the study and contributed to the writing.

\section{REFERENCES}

1. Hussain N, Clive J, Bhandari V 1999 Current incidence of retinopathy of prematurity, 1989-1997. Pediatrics 104:e26

2. Smith LE 2002 Pathogenesis of retinopathy of prematurity. Acta Paediatr Suppl 91:26-28

3. Alon T, Hemo I, Itin A, Pe'er J, Stone J, Keshet E 1995 Vascular endothelial growth factor acts as a survival factor for newly formed retinal vessels and has implications for retinopathy of prematurity. Nat Med 1:1024-1028

4. Pierce EA, Foley ED, Smith LE 1996 Regulation of vascular endothelial growth factor by oxygen in a model of retinopathy of prematurity. Arch Ophthalmol 114:1219-1228

5. Donahue ML, Phelps DL, Watkins RH, LoMonaco MB, Horowitz S 1996 Retinal vascular endothelial growth factor (VEGF) mRNA expression is altered in relation to neovascularization in oxygen induced retinopathy. Curr Eye Res 15:175-184

6. Stone J, Chan-Ling T, Pe'er J, Itin A, Gnessin H, Keshet E 1996 Roles of vascular endothelial growth factor and astrocyte degeneration in the genesis of retinopathy of prematurity. Invest Ophthalmol Vis Sci 37:290-299

7. Aiello LP, Pierce EA, Foley ED, Takagi H, Chen H, Riddle L, Ferrara N, King GL, Smith LE 1995 Suppression of retinal neovascularization in vivo by inhibition of vascular endothelial growth factor (VEGF) using soluble VEGF-receptor chimeric proteins. Proc Natl Acad Sci USA 92:10457-10461

8. Adamis AP, Shima DT, Tolentino MJ, Gragoudas ES, Ferrara N, Folkman J, D'Amore PA, Miller JW 1996 Inhibition of vascular endothelial growth factor prevents retinal ischemia-associated iris neovascularization in a nonhuman primate. Arch Ophthalmol 114:66-71

9. Awata T, Inoue K, Kurihara S, Ohkubo T, Watanabe M, Inukai K, Inoue I, Katayama S 2002 A common polymorphism in the 5'-untranslated region of the VEGF gene is associated with diabetic retinopathy in type 2 diabetes. Diabetes 51:1635-1639

10. Ray D, Mishra M, Ralph S, Read I, Davies R, Brenchley P 2004 Association of the VEGF gene with proliferative diabetic retinopathy but not proteinuria in diabetes. Diabetes 53:861-864

11. Watson CJ, Webb NJ, Bottomley MJ, Brenchley PE 2000 Identification of polymorphisms within the vascular endothelial growth factor (VEGF) gene: correlation with variation in VEGF protein production. Cytokine 12:1232-1235

12. Stevens A, Soden J, Brenchley PE, Ralph S, Ray DW 2003 Haplotype analysis of the polymorphic human vascular endothelial growth factor gene promoter. Cancer Res 63:812-816

13. Prepared by an international committee 1984 An international classification of retinopathy of prematurity. Br J Ophthalmol 68:690-697

14. Yu YS, Heo JH, Hwang SW, Kim JH, Seo JS, Khwarg SI, Chung H 2001 Effect of the absence of heat shock protein 70.1 (hsp70.1) on retinal photoreceptors in normal and rd mice. Korean J Ophthalmol 15:67-73

15. Hawrami K, Hitman GA, Rema M, Snehalatha C, Viswanathan M, Ramachandran A, Mohan V1996 An association in non-insulin-dependent diabetes mellitus subjects between susceptibility to retinopathy and tumor necrosis factor polymorphism. Hum Immunol 46:49-54 